\title{
COVID-19 Infection in a Rare Disease: ROHHAD Syndrome
}

\author{
Banu Çevik, (1) Melike Kuvvet Bilen, (1) Büşra Şabano, \\ (1) Elif Bombacl, (1) Kemal Tolga Saracoglu
}

Department of Anesthesiology and Reanimation, Kartal Dr. Lütfi Kırdar City Hospital, İstanbul, Turkey

Submitted: 21.04 .2021 Accepted: 07.05.2021

Correspondence: Banu Cevik, Kartal Dr. Lütfi Kırdar Şehir Hastanesi, Anesteziyoloji ve Reanimasyon Kliniği, İstanbul, Turkey E-mail: banueler@yahoo.com
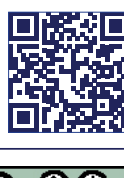

To the Editor,

Rapid-onset obesity with hypothalamic dysfunction, hypoventilation, and autonomic dysregulation (ROHHAD) is an extremely rare disease having a high risk of mortality. Death usually occurs around the age of 10 , but very few patients can survive beyond this age. ${ }^{[1,2]}$ During the novel coronavirus (COVID-19) outbreak, the specific risks for patients with genetic disorders were not fully disclosed; however, available data indicated that they have a more severe course of infection compared to the general population requiring intensive care support. ${ }^{[3]}$ We described the critical care management of a 20 -year-old patient with ROHHAD syndrome presenting with COVID- 19 and discussed the clinical challenges. The patient was admitted to the emergency department with complaints of shortness of breath and fever. His previous history revealed ROHHAD syndrome associated with intellectual delay, severe obstructive sleep apnea requiring continuous positive airway pressure, autonomic nervous system, and endocrine abnormalities. His computed tomography of the thorax demonstrated bilateral ground-glass infiltrates and pulmonary congestion. Laboratory investigations showed leucopenia $\left(1.5 \times 10^{3} / \mathrm{uL}\right)$, hypernatremia $(169 \mathrm{mmol} / \mathrm{L})$, impairment of renal and hepatic function (creatinine: $1.85 \mathrm{mg} / \mathrm{dl}$, blood urea: $84 \mathrm{mg} / \mathrm{dl}$, alanine aminotransferase: $65 \mathrm{U} / \mathrm{L}$, aspartate aminotransferase: $110 \mathrm{U} / \mathrm{L}$, international normalized ratio: 1.82 and prothrombin time: $23.7 \mathrm{sec})$, elevated level of $D$-dimer $(2690 \mu \mathrm{gr} / \mathrm{L})$, ferritin $(63.2 \mu \mathrm{g} / \mathrm{L}), C$ reactive protein (CRP) $(27.4 \mathrm{mg} / \mathrm{L})$ and interleukin-6 (IL-6): $84.39 \mathrm{pg} / \mathrm{ml})$. His nasopharyngeal swab for real-time polymerase chain reaction resulted positive. The patient was initially admitted to the pandemic clinic and the COVID-19 treatment protocol was commenced. However, he developed severe hypoxia that required emergency intubation and was transferred to the intensive care unit three days after hospitalization. He received mechanical ventilation, which required intravenous sedatives with a high fraction of inspired oxygen, high positive end-expiratory pressure, low tidal volume strategy, and concomitant rescue therapies (infusion of neuromuscular blocking agents, prone positioning, and inhaled vasodilators). Nevertheless, he had persistent hypoxemia and respiratory acidosis. Blood glucose levels were consistently high despite the adjusting insulin infusion. Serum sodium level measurements demonstrated fluctuations and required frequent blood sampling and correction of the imbalance. During his course in intensive care unit, his condition gradually deteriorated with hemodynamic alterations refractory to supportive treatment, spiked inflammatory markers (D-dimer: $13.500 \mu \mathrm{gr} / \mathrm{L}, \mathrm{CRP}: 263.6 \mathrm{mg} / \mathrm{L}$, ferritin: $281.8 \mu \mathrm{g} / \mathrm{L}$ and IL-6: $427.2 \mathrm{pg} / \mathrm{ml}$ ), impaired liver and renal function tests. He was not suitable for extracorporeal therapies due to hemodynamic instability and died ten days later in the intensive care unit. Udrea et al. ${ }^{[4]}$ described the first case of COVID-19 infection in a pediatric patient with ROHHAD. Our case is the first described adult case of ROHHAD syndrome presenting with COVID-19 infection. The patient's course was complicated by severe respiratory failure, labile hemodynamics, compromised endocrine system symptoms, and multiorgan dysfunction. Probably due to the underlying autonomic dysregulation, hemodynamics became more unstable during the prone position. This posed a major challenge to improve oxygenation. The blood sodium and glucose levels were difficult to control despite aggressive treatments. Leukopenia was reported as a clinical predictor of poor outcome in COVID-19 patients, ${ }^{[5]}$ so 
pre-existing and refractory leukopenia may also negatively impact the clinical outcome. We need current knowledge about the course of COVID-19 in patients with genetic disorders and their susceptibility to this viral infection. In light of insufficient data, these people are a high-risk population during the pandemic and handling these patients is problematic.

Peer-review

Internally peer-reviewed.

Conflict of Interest

None declared.

\section{REFERENCES}

1. Harvengt J, Gernay C, Mastouri M, Farhat N, Lebrethon MC, Seghaye MC, et al. ROHHAD(NET) syndrome: Systematic review of the clinical timeline and recommendations for diagnosis and prog- nosis. J Clin Endocrinol Metab 2020;105:dgaa247. [CrossRef]

2. NORD (National Organization for Rare Disorders). Rapid-onset obesity with hypothalamic dysfunction, hypoventilation, and autonomic dysregulation. Available at: https://rarediseases.org/rare-diseases/rapid-onset-obesity-with-hypothalamic-dysfunction-hypoventilation-and-autonomic-dysregulation/. Accessed April 19, 2021.

3. Hamad L, Kreidieh K, Nakouzi G, Lyon E, Yazbek S. Recommended measures for the efficient care of patients with genetic disorders during the COVID-19 pandemic in low and middle income countries. Am J Med Genet 2020;182A:2841-6. [CrossRef]

4. Udrea DS, Lopez M, Avesar M, Qureshi S, Moretti A, ABD-Allah SA, et al. Acute COVID-19 infection in a pediatric patient with ROHHAD. Available at: https://www.thieme-connect.de/products/ejournals/pdf/10.1055/s-0040-1718874.pdf. Accessed Oct 14, 2021. [CrossRef]

5. Violetis OA, Chasouraki AM, Giannou AM, Baraboutis IG. COVID-19 Infection and haematological involvement: a review of epidemiology, pathophysiology and prognosis of full blood count findings. SN Compr Clin Med 2020:1-5. [CrossRef] 